\title{
TERRORISMO NUNCA MAIS (TERNUMA): “A FARDA NÃO ABAFA O CIDADÃO NO PEITO DO SOLDADO" 1
}

\author{
Luzimary dos Santos Rocha ${ }^{2}$
}

\begin{abstract}
Resumo
O advento tecnológico iniciado durante o século XX possibilitou o crescimento dos meios de comunicação de massa, no qual está inserido um dos mais relevantes, a tão utilizada Internet, que se consolidou entre as sociedades tornando-se um espaço de entretenimento, meio de comunicação, rede de sociabilidade e disseminador de ideologias e comportamentos políticos. A partir dessas considerações, este trabalho tem por finalidade discutir o uso do Ciberespaço como ferramenta de disseminação de visões político-ideológicas que se traduzem na atualidade em ativismo político de direita em defesa ao Golpe Civil-Militar de 1964. Busca-se nesse contexto, compreender também, a persistência das categorias Direita X Esquerda na atual sociedade brasileira, na identificação e análise de forças sociais que apresentam formas mais complexas de organização política. Para isso, foram utilizados como fonte e objeto, textos escritos e imagéticos do site Terrorismo Nunca Mais (Ternuma), para identificar e explicitar seus objetivos, ideologia e projeto de sociedade através de sua percepção e defesa em torno do Golpe civil-militar de 1964. Tais ações se dão mediante a defesa de ideais patrióticos e aos militares que tomaram o poder em 1964, e também por críticas feitas às práticas dos grupos de esquerda. Dessa forma, fica evidente, são representativas dos confrontos de memórias em torno do Golpe de 1964.
\end{abstract}

Palavras-chave: ciberespaço, ditadura, direita, memória.

\begin{abstract}
The technological advent started during the twentieth century made possible the growth of mass media, which is housed one of the most relevant, the much used the Internet, which was consolidated between societies becoming an entertainment space, means of communication, sociability network and disseminator of ideologies and political behavior. From these considerations, this study aims to discuss the use of cyberspace as dissemination tool of political and ideological views that are reflected today in political activism in defense of the right to civil-military blow of 1964. The aim is to this context, understand also the persistence of Right X Left categories in the current Brazilian society, the identification and analysis of social forces that have more complex forms of political organization. For that were used as source and object, written texts and imagery of the site Terrorism Never Again (Ternuma), to identify and clarify their goals, ideology and social project through its awareness and advocacy around the 1964 Civil-Military coup. Such actions take place through the defense patriotic ideals and the military that took power in 1964, and also criticism of the practices of leftist groups. Thus, it is clear, they are representative of the memories of clashes around the 1964 coup.
\end{abstract}

Key-words: cyberspace, dictatorship, right, memory.

\section{Resumen}

El advenimiento de la tecnología en el siglo XX hizo posible el crecimiento de los medios de comunicación, que ha entrado en uno de los más relevantes, por lo que utiliza el Internet, que se consolidó entre las sociedades convirtiéndose en un espacio de entretenimiento, medios de comunicación, sociabilidad y difusor de la ideología y comportamiento político. De estas consideraciones, este trabajo tiene como objetivo discutir el uso del ciberespacio como una herramienta para la difusión de visiones políticas e ideológicas que hoy en el activismo político de extrema derecha en Defensa Civil-militares golpe de estado de 1964. Buscamos entender también en este contexto, la persistencia de las categorías X izquierdo derecho en la sociedad actual, la identificación y análisis social de las fuerzas que presentan formas más complejas de organización

\footnotetext{
${ }^{1}$ DOI deste artigo: $10.5380 /$ recp.v6i2.44069.

2 Mestranda do Programa de Pós-Graduação em História (PROHIS) da Universidade Federal de Sergipe. Email:yramizul@hotmail.com.
} 
política. Para ello, se utilizaron como fuente y objeto, textos escritos y imagéticos el sitio Terrorismo nunca (Ternuma), para identificar y clarificar sus objetivos, ideología y sociedad de proyecto a través de su percepción y defensa alrededor del golpe civil-militar de 1964. Tales acciones se dan por la defensa de ideales patrióticos y los militares que tomaron el poder en 1964 y también por la crítica de las prácticas de izquierda. Por lo tanto, está claro, son representativos de los enfrentamientos de recuerdos alrededor del golpe de 1964.

Palabras clave: ciberespacio, dictadura, derecho, memoria.

\section{INTRODUÇÃO}

O século XX trouxe muitas transformações para o mundo no âmbito político, social e econômico, atrelado a isso está o surgimento das novas tecnologias, considerada por muitos como um produto do sistema social e do processo histórico, transformou-se em suporte criador de relações sociais, ou melhor, tornou-se geradora de novas práticas sociais. $\mathrm{O}$ advento tecnológico possibilitou a expansão dos meios de comunicação de massa, no qual está inserido um dos mais relevantes: a tão utilizada Internet, esta, por sua vez, consolidou-se entre as sociedades se tornando um espaço de entretenimento, meio de comunicação, disseminador de ideias e novo espaço social.

O computador é uma invenção norte-americana, surgida em meados da II Guerra Mundial e inventada inicialmente para o uso militar com a finalidade de processar cálculos matemáticos e decifração de códigos criptografados. Com a Guerra Fria, o computador passa a ser utilizado como meio de comunicação e controle de informações entre os militares. No final da década de 50, o Departamento de Defesa dos Estados Unidos criou uma agência militar de pesquisa de ciência e tecnologia, a ARPA (Advanced Research Projects Agency), que tinha como objetivo proteger as informações políticas estadunidenses do governo da Rússia. Mais tarde, a ARPA cria um projeto de redes que permitirá a interligação dos computadores das instituições do governo americano. Essa interconexão se daria através do uso de linhas telefônicas, nascendo assim a ARPANET (CARVALHO, 2006, p. 8-11).

$\mathrm{Na}$ década de 70, a ARPANET foi conectada às universidades americanas e estrangeiras, o projeto teve um bom resultado, permitindo assim, a iniciativa de expansão da nova tecnologia que inicialmente foi utilizada por empresas e instituições acadêmicas. Anos mais tarde, a ARPANET ampliará seu desenvolvimento a partir do TCP/IP (Transfer Control Protocol/Internet Protocol) este proporcionaria o crescimento ilimitado da rede. 
Assim, na década de noventa a internet estará disponível para praticamente todos os computadores dos Estados Unidos, o que possibilitou sua disseminação entre a população ${ }^{3}$.

No Brasil, a internet surgiu no final dos anos oitenta tendo sua consolidação no decorrer dos noventa, inicialmente serão restritas às universidades e instituições de pesquisas, mas será também utilizada, pelas instituições governamentais e privadas. O marco da internet no Brasil ocorreu em 1995, período em que o Ministério das Telecomunicações e da Ciência e Tecnologia permitiu o acesso privado à web, sendo liberada sua comercialização à população brasileira. Os primeiros sites a surgirem no Brasil foram os de notícias, posteriormente entretenimento, pesquisa, compras, salas de bate-papo e as tão acessadas redes sociais. ${ }^{4}$

A ampliação da rede pelo mundo resultou no surgimento da Cibercultura e do Ciberespaço. A primeira pode ser compreendida como uma nova cultura, surgida da relação entre tecnologia e sociabilidade, representando, a cultura contemporânea:

Ela nasce nos anos 50 com a informática e a cibernética, começa a se tornar popular na década de 70 com o surgimento do microcomputador e se estabelece completamente nos anos 80 e 90: em 80 com a informática de massa e em 90 com as redes telemáticas, principalmente com "boom" da internet (LEMOS, 2002, p.16).

O Ciberespaço por sua vez, consiste no espaço onde circulam variadas formas de informações que permitem a sociedade a relacionar-se virtualmente, constituindo-se em um espaço formador de novas sociabilidades dando origem a cultura virtual. Pierre Lévy (1997, p. 17) afirma que é um novo meio de comunicação gerado da interconexão de computadores em todo o mundo, segundo ele, o termo não é apenas uma infraestrutura material da comunicação digital, mas também é usado para especificar o universo oceânico de informação abrigado pela comunicação digital.

A web é uma ferramenta muito utilizada pelo homem moderno, seu uso permite inúmeras possibilidades, dentre as quais, está à disseminação de ideologias políticas. No Brasil é possível identificar uma onda crescente de divulgação de ideias e projetos de grupos que se enquadram nas tradicionais categorias de "esquerda" e "direita" a respeito do golpe civilmilitar de 1964 e da ditadura. Eles se expressam na internet através da construção de sites que, entre outras finalidades, buscam defender ou se opor a "memória oficial" do Golpe, tornando-se comuns nas páginas virtuais do Brasil, esses conflitos memorialísticos,

\footnotetext{
${ }^{3}$ Ibidem, p. 18-27

${ }^{4}$ Ibidem, p. 137, 140-144
} 
principalmente no momento atual, de luta pela reparação política daqueles que foram atingidos pela repressão.

Esse trabalho tem por finalidade buscar compreender como o Ciberespaço é utilizado como meio de ativismo político pelas direitas. Perpassando por uma abordagem a respeito das distintas visões disseminadas em relação à tomada de poder pelos militares em 1964, propondo uma discussão em torno das transformações políticas ocorridas em torno da díade "direita" e "esquerda". Buscou-se analisar o site Terrorismo Nunca Mais - TERNUMA (http:/ /www.ternuma.com.br) abordando assim, a formação do grupo e seu posicionamento em relação golpe civil-militar de 1964.

\section{REVOLUÇÃO OU GOLPE DE ESTADO?}

A natureza do golpe ainda é uma discussão em aberto. É possível observar muitos debates em torno do movimento militar, muitas discussões em relação a sua natureza, historiadores, teóricos, militares e militantes ainda debatem sobre o que na realidade foi a tomada de poder realizada pelos militares em 1964. Um espaço bastante utilizado para tais discussões é o ciberespaço, sites em defesa ou em protesto da denominada "Revolução de 1964" ou Golpe Civil - Militar de 1964 circulam nas mídias atualmente. Algumas dessas páginas estão vinculadas a grupos com ideologias de esquerda e direita.

Segundo Norberto Bobbio (2001, p. 51), "esquerda" e "direita" são termos opostos empregados para explicar ideologias distintas pertencentes às ações políticas existentes em toda sociedade. No contexto ao qual se insere essa pesquisa a utilização de tais conceitos decorre das experiências de grupos políticos durante a ditadura militar, e mesmo com as orientações atuais de desuso ou desaparecimento de tais ideologias, percebe-se ao discutir o tema da repressão que os termos ainda permanecem em uso.

Bobbio aponta que são várias as razões que levam a acreditar no fim dessas concepções políticas. No entanto, segundo o teórico, a díade ainda sobrevive apesar das transformações ocorridas ao longo dos anos. Um dos fatores para o desaparecimento dessa classificação foi à crise das ideologias, e de acordo com o autor, "não há nada mais ideológico

\footnotetext{
${ }^{5}$ Esses termos derivam do processo revolucionário Francês do século XVIII onde as tendências políticas que defendiam os interesses do Rei junto a Assembléia nacional sentavam-se a sua direita e as tendências que eram opostas a ele sentavam-se a sua esquerda. Dessa forma, os políticos de "esquerda" apresentavam uma atuação reformista que buscava a conquista de direitos para as classes menos privilegiadas e os políticos de "direita" buscavam os interesses das classes dominantes.
} 
que a afirmação de que as ideologias estão em crise"; outro fator aponta que direita e esquerda não são apenas programas ideológicos, mas projetos opostos correlacionados a vários problemas cuja solução pertence à ação política, não apresentam apenas ideias divergentes, mas projetos de sociedades diferentes, que de acordo com o autor, não podem ter desaparecido facilmente ${ }^{6}$.

Em um dos seus argumentos para provar que a díade ainda sobrevive, Norberto Bobbio defende que as expressões continuam a ter pleno curso na linguagem política. E que mesmo com os questionamentos sobre o futuro da esquerda e sua renovação, e o surgimento de uma nova direita, os partidos políticos ainda continuam sendo divididos e classificados em duas correntes que ainda costumam ser chamadas de "esquerda" e "direita". Para o autor, em um universo como o do político, formado por antagonismos onde há partes contrapostas, o modo mais simples de representar essas relações, sempre foi por meio de díades ou dicotomias, onde há dois lados contrapostos. Dessa forma, dentro do universo político veremos o uso de metáforas espaciais e temporais indicando se determinado grupo está próximo, distante da esquerda, direita, ou se é conservador ou progressista, esses termos substituem os dois polos, mas não farão com que desapareçam ${ }^{7}$.

Bobbio define a igualdade como uma questão importante na análise da oposição direita e esquerda. Igualdade é uma característica que identifica às esquerdas, isto não significa que há busca por igualdade em tudo, mas que suas ações e programas de governo apresentam questões mais igualitárias que a direita. Dessa forma, para os igualitários as desigualdades são sociais e, portanto, suscetíveis à eliminação; já os inigualitários acreditam que as desigualdades são naturais e inelimináveis. Esse último pensamento, de acordo com o autor, está ligado à direita, pois a mesma acredita que as desigualdades são naturais ${ }^{8}$.

O Golpe de Estado que ocorreu no Brasil em 1964 se construiu em torno do conflito gerado entre a direita e a esquerda, identificadas a partir do embate entre forças capitalistas e socialistas, o primeiro defendido pelos Estados Unidos e o segundo pela Rússia e baseado na Doutrina de Segurança Nacional que foi propagada pela Escola Superior de Guerra. A DSN tinha como uma de suas principais bases a elaboração do pensamento de contenção comunista internacional, inspirada na Doutrina Trumam, que defendia a ideia de que os

\footnotetext{
${ }^{6}$ Ibidem, p. 33

${ }^{7}$ Ibidem, p. 63-69

${ }^{8}$ Ibidem, p.105
} 
exércitos dos países subdesenvolvidos deveriam ser liderados pelo bloco capitalista dos EUA, com o objetivo de cuidar da defesa interna contra a "subversão" comunista: "A fronteira a ser defendida passaria a ser ideológica (e não mais geográfica) e o inimigo seria, primordialmente, um "inimigo interno", que poderia ser qualquer cidadão simpatizante ou militante do comunismo" (NAPOLITANO, 2014, p. 10).

João Goulart ao assumir o poder defendeu as reformas de base, no qual pregava mudanças em âmbito social, econômico e político, para a construção de um Brasil menos desigual e mais democrático. Considerado pela "direita" como amigo dos comunistas, e pelas "esquerdas" como um governo conciliador, o até então presidente passou a ser pressionado pelos dois lados: por parte dos conservadores pela implantação de uma reforma moderada, e pelas esquerdas que queriam a realização das reformas de base em caráter urgente. Para Marcos Napolitano (2014, p.10), “o golpe foi o resultado de uma profunda divisão na sociedade brasileira, marcada pelo embate de projetos distintos para o país, os quais faziam leituras diferenciadas do que deveria ser o processo de modernização e de reformas sociais".

A ala conservadora da burguesia e das Forças Armadas, assim como a esquerda radical, pregava uma "revolução". Mas qual o sentido de revolução para essas forças políticas? Ambos defendiam revoluções com sentidos distintos. Para os partidos conservadores, a revolução dos militares estava defendendo o país dos interesses comunistas e prevenindo a nação de uma futura guerra civil ou de um Golpe de Estado que seria realizado por Jango, que presidia o Estado em um regime comunista. Desse modo, ao tomarem o poder estavam realizando a "vontade do povo", que se colocava na oposição a João Goulart e qualificava as Forças Armadas como seu representante na luta contra a corrupção, subversão e defesa da democracia: "O Estado, então, passa a encarnar a vontade da nação e do povo, estar a serviço do bem comum, e, portanto, situa-se acima dos interesses particulares de grupos ou de classes sociais, definindo seus fins e adaptando seus meios." (CARDOSO, 2011, p. 20).

As esquerdas brasileiras apresentaram uma cisão de seus interesses e a ala formada pelo PCB defendia um modelo de governo democrático baseado em reformas sociais, a ala radical formada pelo PC do B, ligas camponesas e pequenas agremiações defendiam uma a revolução que seria pautada em um novo sentido para a democracia, tendo como modelo os regimes: soviético, cubano e chinês. Bobbio (1998, p. 1121) difere revolução de golpe de estado, no sentido que o último se configura numa tomada de poder das autoridades políticas 
sem nada ou quase nada mudar nos mecanismos políticos ou sócio - econômicos e a revolução só se consolida com profundas mudanças no sistema político, social e econômico.

José Luiz Fiorin (1988, p. 23-25) defende que o discurso político é persuasivo, e no contexto político social de 1964, teremos um discurso por parte dos militares, regido pela transformação do "caos" em "ordem" e englobando esse "caos", estariam: desordem, desgoverno, inflação, a anarquia e na "ordem”: disciplina, desenvolvimento, honestidade. As reformas políticas seriam o produto de tal desordem, e a "revolução" feita por eles traria "ordem" ao Brasil e sufocariam o "grande caos", este seria por sua vez o comunismo. Esse discurso será estabelecido pela oposição entre "nós" e "eles". Dessa forma, todo oposicionista foi visto pelo governo como traidor, essa interpretação desencadeou e justificou a repressão contra a oposição. O “outro”, nesse caso a esquerda, será o responsável pelas ações repressivas do governo sendo possível devido sua radicalização de ações.

Com finalidade de descaracterizar a ideia de golpe, os militares se utilizaram do discurso de que o povo (sujeito que delega o poder) transferiu o poder para as Forças Armadas, que por sua vez, destituiu o então presidente, e legitimou a vontade da nação tal como ocorre no processo democrático, logo houve uma "revolução" e não um Golpe de Estado como as esquerdas tanto acusaram. Uma característica dos enunciados desses discursos é a ideia de que o brasileiro é um povo pacífico e ordeiro, de natureza conservadora e avessa a alterações na lei e na ordem: “(...) nosso homem ufana-se da pátria, não vendo nela qualquer elemento negativo nem qualquer coisa a alterar"”. Dessa maneira, a classe dominante disseminava seu projeto às outras classes, mostrando que qualquer transformação social seria impossível, uma vez que, o sistema aqui implantado era "natural" e de origem coletiva, pois a nação brasileira o queria dessa forma.

O discurso "revolucionário", defendido pelo Exército, afirmava que Goulart colocou o país a beira do caos, que havia estagnado a economia e subvertido a ordem, tendo ainda planejado instaurar uma ditadura comunista. Dessa forma, ao tomarem o poder os militares estavam recuperando o país do caos e realizando uma revolução. Para Fiorin, o movimento não passou de uma "contrarrevolução", pois os militares visavam à manutenção de uma ordem capitalista que, segundo eles, estava prestes a ser destruída. Revolução é o movimento contrário à ordem estabelecida, e o movimento de março não possuía essa característica, pois pretendia recolocar o país no caminho da ordem vigente. Classes hegemônicas não fazem

${ }_{9}^{9}$ Ibidem, p. 40 
revolução, mas contrarrevolução, para retirar as classes subalternas da cena das decisões políticas $^{10}$.

Dentro dessa discussão em torno do real sentido da Ditadura de 64, também está o debate entre estudiosos que divergem sobre o sentido do golpe de estado. O estudo de René Armand Dreifuss, intitulado 1964: A conquista do estado, ação política, poder e golpe de classe, incorporou a expressão golpe civil - militar a bibliografia sobre o tema. A designação de golpe militar até então dominante na literatura, passou a ser questionada e foi considerada insuficiente, a partir de uma extensa documentação, Dreifuss mostrou que importantes atores da sociedade foram decisivos na preparação e execução do movimento militar. De acordo com ele, o golpe foi articulado pela burguesia industrial em conjunto com os militares. Ao fazer tal afirmação, fica claro que a ação dos militares não foi orquestrada apenas pelas Forças Armadas, mas em conjunto com as elites que dispunham de meios estratégicos para consolidar a derrubada do governo (TOLEDO 2006, p. 120).

Caio Navarro Toledo ${ }^{11}$ afirma que Dreifuss mostrou como a formação ideológica é importante dentro da articulação política, uma vez que a ação das elites não tinha apenas objetivos políticos dentro dessa conjuntura, mas também objetivação ideológica. Os meios pelos quais seus ideais seriam efetivados seriam através do complexo IPES (Instituto de Pesquisas e Estudos Sociais) e IBAD (Instituto Brasileiro de Ação Democrática), formado por empresários de multinacionais e militares associados aos ideais norte-americanos.

A história do complexo IPES/IBAD relata o modo pelo qual a elite orgânica da burguesia multinacional e associada evoluiu de um limitado grupo de pressão para uma organização de classe capaz de uma ação política sofisticada, bem como o modo pelo qual ela envolveu da fase de projetar uma reforma para o estágio de articular um golpe de Estado (DREIFUSS, 1986, p.161-162).

O IPES tinha uma defesa de política dupla, aos olhos da sociedade se mostrava como uma organização de empresários respeitáveis, instituindo-se num "grupo apartidário" que tinha como principais objetivos educação cívica, social e cultural entre seus indivíduos e através disto contribuir para o desenvolvimento econômico e social e fortalecimento da democracia brasileira. Clandestinamente atuava numa ação planejada contra o governo reformista de Jango e contra as camadas sociais que o apoiavam, para isso se empenhavam na união de grupos que eram contra os ideais desse governo, inclusive penetrando em grupos sindicais e estudantis e contando ainda com uma importante força dentro do Congresso para

${ }^{10}$ Ibidem, p.62
${ }^{11}$ Idem 
conter as ações do governo e das esquerdas. Se utilizando do complexo IPES/IBAD, a burguesia se preparou para agir em toda a vida social e política do povo brasileiro a partir de meios legais e ilegais, que intencionavam a deposição do Presidente. Sua ação deu-se através da criação de uma ideia de caos econômico e social, bloqueando as ações das esquerdas e deturpando os ideais comunistas ${ }^{12}$.

A ação das elites ocorreu através de medidas tanto no campo ideológico e social como político militar. Dentro do campo ideológico visavam apresentar ideias, que tinham a finalidade de criar uma impressão negativa do bloco popular - nacional reformista, trazendo à tona as ideias tradicionais de "direita" vistas como a "solução" para a nação brasileira. A doutrinação ocorria através dos meios de comunicação, de peças teatrais, desenhos animados, filmes, artigos de jornais, seminários, congressos. Esses dispositivos eram utilizados como meios de disseminar os ideais políticos e sociais da burguesia e construir uma imagem negativa dos grupos de esquerda, assim como do então presidente João Goulart (DREIFUSS, 1986, p. 232).

Dessa maneira, se mostra como foi construído o ideário da "direita" em torno da disputa pelo poder, na qual através de ações estratégicas visavam minar as ações reformistas do governo de Jango e a crescente atuação da esquerda, para assim dar voz ao discurso pautado no desenvolvimento capitalista ligada à ação militar.

O processo ideológico que permeou os acontecimentos de 1964 serviu como embasamento para a construção dessa pesquisa. A ênfase na formação ideológica tornou-se necessária para entendermos os discursos travados no mundo virtual, que ganharam força no mundo real, pois ainda hoje a direita defensora do golpe se manifesta em defesa dos seus ideais e de seus enunciados. No que diz respeito ao que foi realmente tal ação, Golpe de estado, Revolução ou Contrarrevolução, Golpe Militar ou Civil- Militar, não restam dúvidas que, no Brasil, como em outros países do Cone Sul, o que de fato ocorreu foi um Golpe de Estado articulado pela alta burguesia em acordo com alguns militares, que instaurou uma ditadura que durariam 21 anos.

${ }^{12}$ Ibidem, p. 126-127 


\section{TERRORISMO NUNCA MAIS E A “REVOLUÇÃO” DE 1964}

A memória consiste numa operação coletiva de acontecimentos e das interpretações do passado que se quer salvaguardar. Servindo como um fator fortalecedor do sentimento de pertencimento ao um determinado grupo e fronteira sociais. Assim, defende-se que a referência ao passado serve para manter a coesão dos grupos e das instituições que compõe uma sociedade para definir seu lugar respectivo. (POLLAK, 1989, p. 7-8).

Jacques Le Goff (1996, p. 426) afirma que a memória coletiva tornou-se importante na luta das forças sociais pelo poder. Dessa maneira, aquele que detêm o poder torna-se "senhor da memória" manipulando-a para seus interesses. Assim, os esquecimentos e silêncios da história são reveladores desses mecanismos. O processo de transição política brasileira apresentou essa característica definida por Le Goff. No entanto, apesar de ser uma transição baseada em acordos e encobrimentos, foi possível para esquerda torna-se a memória dominante, em relação aos fatos ocorridos durante a Ditadura, e aquela representada pelos militares tornou-se alvo de críticas.

No entanto, numa tentativa de resgatar e defender suas ações durante a repressão, alguns militares da reserva e civis passaram a produzir materiais no qual abordam suas versões dos fatos ocorridos no período ditatorial. Essa produção memorialista se apropriou do conhecimento dos "bastidores da política", uma vez que eles estavam no poder, como forma de afirmar que seu olhar sobre os acontecimentos era o mais “fidedigno", por serem capazes de revelar documentos e segredos da política, estando dessa forma, contribuindo para a construção de uma história "verdadeira": "A ideia de preservar a "memória pública" e "salvar a nação" somam aspectos relevantes no processo dos memorialistas do poder, pois na visão deles constitui o próprio sentido de investirem na tarefa árdua de escreverem os seus depoimentos" (CARDOSO, 2012, p 43).

O grupo Terrorismo Nunca Mais (TERNUMA) foi criado no ano 1998, por um grupo de civis e alguns militares da reserva, em resposta as ações da entidade Tortura Nunca Mais e e as atitudes desfavoráveis de algumas autoridades públicas em relação à história da "Revolução de 1964", pois durante a década de noventa foram aprovadas algumas leis consideradas relevantes no combate aos crimes sofridos por alguns militantes durante a repressão, dentre as quais se destaca a Lei N. ${ }^{\circ}$ 9.140, de 4 de dezembro de 1995, que reconheceu como mortas as pessoas desparecidas durante a Ditadura Militar e concedeu 
indenização às vítimas ou familiares das vítimas. A Lei também foi responsável pela instituição da Comissão Especial sobre Mortos e Desaparecidos Políticos ${ }^{13}$.

Em seu discurso o TERNUMA afirma que foi criado com a finalidade de mostrar ao povo brasileiro qual é a "verdadeira história da revolução de 64". O grupo denomina-se uma instituição não governamental (ONG), possuindo sede em Brasília. Assemelhando-se ao grupo Tortura Nunca Mais, mas atuando em sentido oposto, o grupo elaborou o seu próprio estatuto $^{14}$, no qual estabelece como objetivos: esclarecer e denunciar os atos políticos realizados pelos terroristas (grupo de esquerda) durante o regime militar, com a finalidade de extinguir os privilégios concedidos; combater ideologias que ameacem os princípios democráticos; promover e incentivar manifestações patrióticas e a discussão de assuntos nacionais; apoiar a assegurar as vitimas e familiares dos atos cometidos pelos ditos "terroristas" e "estimular a criação de regionais do TERNUMA em todo o território nacional".

As ações do TERNUMA estão voltadas para a defesa da memória dos militares, tendo como Patrono o General Emilio Garrastazu Médici, presidente do Brasil no auge da repressão política. Esse grupo tem como principal meio divulgador de suas ações o site da entidade denominado TV TERNUMA (www.ternuma.com.br), onde são publicados artigos, documentos e vídeos sobre o período da ditadura e sobre assuntos da política atual.

O site do grupo Terrorismo Nunca Mais (http://www.ternuma.com.br) foi criado durante os anos 2000, concebido a partir da análise de temas sobre a política brasileira atual: corrupção, Comissão Nacional da Verdade, política externa e o Golpe Civil-Militar de 1964, defendido como a "revolução de 1964". Disponibilizam artigos, imagens e vídeos sobre essas temáticas. Quase sempre, se consideram apartidário, ou seja, não estão vinculados a nenhum partido político, no entanto, as postagens presentes no sitio são de cunho político e a favor da ordem capitalista e do autoritarismo. Posicionam-se contrários à atuação das esquerdas, ao atual governo, e favoráveis as ações militares, sendo um dos principais objetivos de sua militância "mostrar ao povo brasileiro a verdadeira história do movimento militar".

\footnotetext{
${ }^{13}$ Texto disponível no site [http://www.sdh.gov.br/assuntos/combates-as-violacoes/historico-do-combate-atortura-no-brasil]. [Acesso em 20 de setembro de 2015].

${ }^{14} \mathrm{O}$ estatuto do grupo foi registrado em Brasília e o documento pode ser encontrado na página do Ternuma, disponível em PDF, através do link: [http://www.ternuma.com.br/index. php/nosso-estatuto]. [Acesso em 10 de outubro de 2013].
} 
TV TERNUMA conta com mais de mil artigos em constante expansão e atualização, e outras informações postadas semanalmente, como vídeos, áudios, imagens. Artigos presentes no site são escritos por militares e civis filiados ao Grupo Terrorismo Nunca Mais, a página e também compartilha textos de outros sites e blogs e de notícias, de orientação de direita ou não.

$\mathrm{Na}$ página inicial desse site, estão os linkes de apresentação do grupo, estatuto da organização, área para se cadastrar na entidade e para fazer doações. Também há os links: Memorial 31 de março, que disponibiliza uma lista com os nomes das vítimas das ações da esquerda durante as décadas 60 e 70, e em uma determinada parte eles perguntam - Onde eles estão (?), referindo-se aos militantes de esquerda que atuaram durante o período da ditadura. O intuito aqui é disponibilizar fichas com nomes, profissões, partidos e trajetórias políticas dos membros das esquerdas ou oposicionistas, desde o período ditatorial até os dias atuais. Em seguida, encontra-se o link: Revanchismo, que disponibiliza alguns artigos centrados nas ações consideradas "revanchistas" das esquerdas contra os militares. A temática do Justiçamentos- rendeu-lhes outro link referente à atuação política das esquerdas. "O justiçamento foi empregado para assassinar os próprios comunistas considerados traidores e os seus inimigos, os integrantes das forças legais de segurança e todos aqueles que com elas colaboravam". Ademais, os links Baú da verdade, Contraponto e Para Meditar, foram elaborados com o mesmo objetivo de mostrar a "verdadeira" versão dos fatos ocorridos durante a Ditadura.

Apesar do vasto acervo disponibilizado na página, as temáticas discutidas pela TV TERNUMA, em sua maioria, circundam em torno da questão do movimento militar de 1964 e as práticas memorialísticas dos governos pós-ditadura. Além dessas abordagens, o site também analisa temas da situação política atual do Brasil, através disso o TV TERNUMA procura deixar claro sua ideologia de oposição às ações do governo petista.

O "Baú da verdade", nome do link no qual o site se propõe a mostrar "algumas verdades" sobre os fatos ocorridos durante a ditadura, traz como texto de abertura o seguinte enunciado: "a mentira, travestida de verdade, sempre foi a maior arma da esquerda", e que a mesma, sempre respaldou as ações da esquerda desde os fatos ocorridos na Rússia até as ações no Brasil. E que a juventude do Brasil está influenciada pela ideologia dos grupos de esquerda, que de todas as formas e, particularmente pela educação, inverte e distorce os fatos reescrevendo a História de acordo com a ótica "revanchista". Para o sitio, o Baú da verdade tem como objetivo mostrar a realidade que é escondida ao jovem e a nação brasileira. "A 
história foi reescrita pela falaciosa propaganda desenvolvida pela esquerda brasileira, que de maneira messiânica, segundo os padrões de Antonio Gramsci, colocou os ‘bandidos' no lugar de 'mocinhos"'. Esses padrões gramiscinianos referem-se ao pensamento marxista, que sustenta muitos dos ideais e utopias presentes no meio acadêmico brasileiro ${ }^{15}$.

O site afirma que mesmo após o decreto da anistia que permitiu a volta dos "comunistas" ao país, assim como a sua integração na vida política, muitos deles ainda hoje perseguem os que defenderam a "revolução". Essa ação praticada pela esquerda é intitulada pelo site de revanchismo. No final da mesma, há uma lista intitulada de "Lista de Verdades Históricas", nesse espaço são postados alguns materiais, pequenos textos, artigos que tem como objetivo desmentir algumas versões da esquerda. Inserida nos assuntos retratados pelo TV TERNUMA está à questão da defesa do golpe como uma revolução, a página faz uma ampla abordagem dessa temática em constante defesa das ações dos militares durante os anos de repressão.

Durante o cinquentenário do Golpe Civil-Militar de 1964, o site postou vários artigos em comemoração ao movimento, além de outras atividades como a celebração de uma missa. Os artigos postados nesse sitio sobre a temática da "Revolução" apresentam em geral a mesma ideologia, colocando-se em defesa das ações dos militares durante os anos de 1960, e em contrapartida, acusando as esquerdas de "deturparem" a versão dos fatos.

Desse universo de informações apresentado pelo TV Ternuma, destacaram-se alguns artigos reveladores de sua ideologia político-militar. O texto intitulado "O regime militar alcançou todos os objetivos do Movimento de 1964? (2014)" foi escrito pelo General da Brigada do Exército Paulo Chagas ${ }^{16}$, atual presidente do Grupo TERNUMA. Para o autor, o primeiro objetivo dos militares na tomada de poder em 64 foi manter a democracia, visto que o mundo estava polarizado entre comunistas e democratas (capitalistas) e no Brasil os comunistas já estavam no governo, faltando-lhes apenas o poder o que seria obtido através do golpe.

Argumenta ainda, que os comunistas, embora em minoria, estavam organizados e atuantes e já se preparando para a tomada de poder. "A imensa maioria da sociedade

\footnotetext{
15 O texto encontra-se na parte final do link Baú da verdade, e abaixo dele são listados alguns artigos que pretendem falar a "verdade dos fatos", como "os norte-americanos não tramaram a contrarrevolução de 31 de março de 1964” e "UNE: organização-pelego, de Getúlio a Lula.

${ }^{16}$ Paulo Chagas nasceu no Rio de Janeiro e atualmente mora em Brasília. Foi da Academia Militar das Agulhas Negras e trabalhou no $1^{\circ}$ Regimento da Cavalaria de Guardas.
} 
condenava a baderna que se instalava no País e temia a "cubanização", em consequência acolheu com alegria e ufanismo a iniciativa dos militares, o que ficou largamente registrado nas manchetes dos jornais da época" ${ }^{" 17}$. Segundo Chagas (2014), mesmo frustrada a esquerda colocou em prática o "plano B", este seria efetivado através da luta armada objetivando a tomada do poder das mãos dos militares. Chagas afirma que as ações terroristas da esquerda armada tiveram início desde cedo e que logo se intensificaram na medida em que se obtinha "sucesso", como no caso da explosão de bombas no Aeroporto Guararapes (Recife), que "obrigou" o governo a endurecer o regime.

O dirigente do TV TERNUMA defende que os conflitos armados desencadearam um excesso de ambos os lados, mesmo assim a censura não impediu manifestações e muito menos interferiu na ação da justiça. Defende ainda que durante os anos de ditadura o rigor no cumprimento das leis, e a ordem instaurada permitiu um ambiente de segurança e otimismo que possibilitou o crescimento do país. Para Paulo Chagas, o regime durou mais que o previsto, devido às ações dos "terroristas" (grupos de esquerda), no entanto é lícito afirmar que o regime "alcançou seus objetivos, particularmente o principal, que seria a preservação da democracia". A melhor prova disso seria o fato de a esquerda estar no poder atualmente, sendo eleitos de forma democrática devido à ação dos militares.

O texto "31 de março de 1964 - Uma data a ser lembrada" (2014) ${ }^{18}$, escrito pelo general Pedro Luis de Araujo Braga". Também homenageiam os 50 anos da "Revolução de 1964", afirmando que o "Movimento cívico Militar" ou a "Revolução Democrática” salvou o Brasil de um caos. Ele conclui afirmando:

O Brasil, que nasceu sob a sombra da cruz e que, como diz o cancioneiro popular, "é bonito por natureza e abençoado por Deus”, será sempre uma nação cristã, fraterna e acolhedora, amante da paz, livre e democrata. Jamais será dominada pelos comunistas, mesmo que isto custe à vida de muitos. É o nosso compromisso! 20

\footnotetext{
${ }^{17}$ CHAGAS, P. O regime militar alcançou todos os objetivos do movimento de 1964? TV TERNUMA. 2014. Disponível em: [http://www.ternuma.com.br/index.php/art/1893-o-regime-militar-alcancou-todos-osobjetivos-do-movimento-de-1964-pchagas]. [Acesso em: 10 de abril de 2014].

18 BRAGA. P. L de A. 31 de Marco de 1964 - Uma data a ser lembrada, 2014. Disponível em: [http://www.ternuma.com.br/index.php/art/1872-31-de-marco-de-1964-gen-braga-sensaciona]. [Acesso em: 01 de abril de 2014].

19 Pedro Luis de Araujo Braga é General Reformado do Exercito e presidente do Conselho deliberativo do Clube Militar.

${ }^{20}$ BRAGA, P. L de A. op.cit
} 
O General prossegue narrando que os vencidos, nesse caso a esquerda brasileira, que recebeu a anistia oferecida pelos militares, hoje rotulam o movimento de "Golpe Militar" e de Ditadura Militar. O militar, ainda, acusa a mídia de "que não tem compromisso com a verdade" porque manipula e deturpa a história da "revolução". Para defender o posicionamento de que essa não foi uma ditadura, o general defende de que não poderia ser uma ditadura porque os presidentes foram eleitos por meio do voto indireto no Congresso e de que muitos países democráticos adotam esta forma de governo, como também, naquela época, os jornais de oposição circulavam livremente, como o Correio da Manhã do Rio de Janeiro, que circulou sem censura do governo.

O Correio da Manhã apresenta uma característica peculiar em relação à Ditadura Militar, pois teve participação intensa no processo de deposição de João Goulart e após decretação do Golpe de 1964 o jornal passou para oposição. Juremir Machado da Silva (2014, p. 32), afirmou que a imprensa teve um papel importante na derrubada de João Goulart do poder: "Os grandes jornais de cada capital atuaram como incentivadores e árbitros. Um dos mais ferrenhos estimuladores do golpe foi o jornal carioca Correio da Manhã que rapidamente perceberia o erro e passará a oposição, perecendo durante o regime militar”".

O Correio da Manhã estava entre os jornais mais importantes e de maior circulação no Rio de Janeiro até 1950, quando foi ultrapassado pelo Jornal do Brasil. Ideologicamente ligado com as classes médias conservadoras e liberais, o Correio da Manhã fez forte oposição ao governo de João Goulart defendendo sua deposição. No entanto após o Golpe se tornou referência para os setores da esquerda. O jornal criticou as reformas de base defendidas por Goulart, através do editorial Equívocos que defendeu as reformas, não no modelo trabalhista e sim com um caráter modernizador que possibilitaria progresso econômico e social ao povo brasileiro.

As tensões entre jornal e Goulart se acentuaram quando o governo criou um projeto que visava a possibilidade de monopólio estatal da importação e da distribuição de papel para os jornais, para o Correio da Manhã, isso sufocaria a crítica livre. Porém, o que estava por trás eram questões políticas e econômicas, pois as medidas defendidas pelo governo acarretariam na alta dos preços e aumento no custo de produção o que possibilitaria uma queda nos lucros. Em 31 de março e $1^{\circ}$ de abril, através dos editoriais Basta! e Fora, o jornal defendeu a deposição imediata do presidente argumentando que as medidas tomadas por Goulart estariam desrespeitando a Constituição de 1946 e as eleições de 1965. Após o Golpe CivilMilitar, o jornal passou para a oposição com a criação do AI-I, pois apesar do apoio ao 
movimento militar, se colocava contra ao regime de repressão que se estabelecia no país. $\mathrm{O}$ Correio Manhã prosseguiu criticando o governo militar até 1968 quando passou a ser perseguido pelos militares. E após a retirada do apoio financeiro das empresas privadas e do poder público, em 1969 o jornal foi arrendado por novos proprietários que seguiram uma linha governista, contudo o jornal fechará as portas em 1974. (CHAMMAS, 2011, p. 5-9)

General Braga prossegue reforçando o discurso situacionista ao argumentar que o Brasil estava em estado crítico antes de 1964. E que a nação pediu a "vitoriosa intervenção militar", que instaurou um novo regime "sem derramamento de sangue", diferente dos demais países com regime comunista.

Eram greves em atividades essenciais, desabastecimento, inflação galopante, comícios ameaçadores, serviços públicos em crise, as intimidações da CGT. E a Nação, cuja voz era a voz de Deus, aflita, temerosa, apelou para suas Forças Armadas - povo fardado que sempre, ao longo dos tempos, estiveram ao seu lado, pois nunca foram intrusas na História Pátria. Como bem escreveu o lendário Osório, "a farda não abafa o cidadão no peito do soldado". Sempre é bom lembrar à extraordinária "Marcha com Deus e a Família pela Liberdade", que congregou, em passeata cívica e ordeira, um número incontável e inimaginável de bons brasileiros, de iniciativa e coordenação de Senhoras da sociedade ${ }^{21}$.

O general continua reforçando no texto "31 de março de 1964- Uma data a ser lembrada" que os militares apenas realizaram as ordens de seus superiores na "defesa" da democracia, portanto, não cabe o rótulo de "torturadores" dado pelas esquerdas, que atualmente se apresentam como "heroínas da nação", sendo que os seus únicos interesses estão nas "indenizações" que recebem. Essas mesmas esquerdas, segundo o autor, nos tempos atuais são acusadas de "crimes de corrupção", no entanto em relação aos militares, suas obras só mostram que sempre foram "honestos".

Esse texto compõe e exemplifica o vasto acervo de artigos da página virtual do grupo Terrorismo Nunca Mais. Além disso, é revelador das disputas de memórias entre situacionistas e oposicionistas em tempos de transição democrática, bem como impressiona a forma de permanência dos princípios básicos da Doutrina de Segurança Nacional (DSN), principalmente no que diz respeito à bipolaridade entre os dois mundos (comunista X socialismo) e a perseguição ao "inimigo interno", identificado como "subversivo" ou "terrorista", que hoje, mais do nunca, ocupa cargos influentes na administração pública, estando geralmente envolvidos em atos de corrupção.

${ }^{21}$ BRAGA, P.L de A. op.cit 
Em defesa dos militares no poder, o jornalista Alexandre Garcia ${ }^{22}$ escreveu o texto “31 de março, Abordagem clara, análise coerente e imparcial (2014)”. Ele se refere aos 50 anos do golpe, afirmando que as ações militares são maculadas ou deturpadas. Para o jornalista, o comunismo a maneira cubana é repressivo e autoritário e a grande verdade é que o "golpe ou revolução de 64 livrou ou talvez tenha livrado o país dessa situação". Em relação à guerrilha, o autor opina que respeita tal atividade, mas não apoia. Para ele, foi uma "guerra suja", causada pelas esquerdas, provocadora de dualidades: vilões representados pelos militares e heróis pela esquerda militante. Diz, ainda, que não deve existir tal dualidade, mas em uma guerra formada por lados opostos deve-se haver o respeito.

Esse respeito, entretanto. Só existiu de um lado. Porque à esquerda, amargurada pela derrota e pela pequenez moral de seus líderes nada mais fez nos anos que se seguiram, do que pisar na memória de suas Forças Armadas. E assim seguem fazendo. Jogando na lama a honra dos que tombaram por este país nos campos de batalha. E contaminando a maneira de pensar daqueles que cresceram ouvindo as tolices ditas pelos nossos comunistas. Comunistas que amam Cuba e Fidel, mas que moram nas suas coberturas e dirigem seus carrões. Bem diferente dos nossos militares, diga-se de passagem ${ }^{23}$.

Tal ação, para o autor, contribui para que os jovens não tenham respeito pelas autoridades e que os políticos que estão no poder não passam de “escoria”. Alexandre Garcia fala em imparcialidade, mas a todo tempo deixa explicito que as ações militares foram corretas, que os mesmos não cometeram crime algum, estavam apenas fazendo seu trabalho e quando ele se refere às esquerdas, deixa subtendido que está fazendo uma crítica ao Partido dos Trabalhadores, definido no texto como "escoria". Dessa maneira, se nota que diferente do título, o autor em todo o artigo não é imparcial, mas contrário às ações dos grupos de esquerda e defende a tomada de poder por parte dos militares em 1964.

As postagens presentes no site obedecem ao objetivo principal do grupo de mostrar para o povo brasileiro o outro lado da história, a "verdadeira versão" dos fatos acorridos durante a denominada “revolução de 1964". Por isso, para o grupo está explícito que de fato ocorreu uma revolução. Em sua maioria, os artigos postados no site se referem às ações dos grupos de esquerda durante a ditadura. Dessa forma, o TV TERNUMA faz uma ampla

\footnotetext{
22 Alexandre Eggers Garcia é um jornalista, apresentador, comentarista de telejornais, colunista político e conferencista brasileiro. Atuou no Jornal do Brasil, no Fantástico e na extinta TV Manchete, e atualmente é diretor de jornalismo da TV Globo Brasília. Na Presidência da República, foi Porta-Voz do último presidente militar do Brasil, General João Batista Figueiredo.

23 GARCIA, A. 31 de Marco, Abordagem clara, análise coerente e imparcial. 2014. Disponível em: [http://ternuma.com.br/index.php/art/1875-31-de-marco-abordagem-clara-analise-coerente-e-imparcial] [Acesso em: 10 de fevereiro de 2015].
} 
exploração da questão do "revanchismo", afirmando que os militares vivem sob perseguição das esquerdas brasileiras e que as recentes discussões sobre os crimes de torturas que envolvem a Guerrilha do Araguaia, revisão da Lei de Anistia e criação da Comissão da Verdade, são resultados da "política revanchista" presente no Brasil desde que as esquerdas assumiram o poder.

A defesa aos ideais patrióticos e aos militares que tomaram o poder em 1964, assim como as críticas feitas por esse site às práticas dos grupos de esquerda, são representativas dos confrontos de memórias em torno do Golpe de 1964, tanto por parte daqueles que retrataram as ações voltadas a "salvaguarda da memória" daqueles que atuaram a favor do Regime de 1964, como também por aqueles que militaram ou denunciaram os crimes cometidos por alguns militares durante os "anos de chumbo". O governo federal, desde a gestão de Fernando Henrique Cardoso procurou desenvolver uma política de memória, que resultou em tentativas de revisão da Lei da Anistia, abertura de acervos de documentos da repressão, criação da Comissão Nacional da Verdade, entre outros. Essas iniciativas não foram bem vistas pelo Grupo Terrorismo Nunca Mais, tendo muitos dos seus pontos criticados no interior do Sitio.

Questões que permeiam Golpe Civil-Militar de 1964, ainda são recorrentes na sociedade brasileira e no meio acadêmico, muitas versões foram criadas em torno dos fatos ocorridos durante a repressão. No entanto, ainda há uma ocultação dos fatos, muitas questões permanecem em aberto e em constante discussão na sociedade brasileira. Em torno dessa problemática, percebe-se no Brasil, o ressurgimento de ideologias políticas e de uma memória defensora do golpe, o TV TERNUMA por sua vez, atua como um elemento disseminador desses ideais.

\section{REFERÊNCIAS}

BOBBIO, Norberto. 2001. Direita e Esquerda: razões e significados de uma distinção política. São Paulo: Editora UNESP. 1998. Dicionário de Política. Brasília, DF: Ed. UNB.

BRAGA. P. L. de A. Uma data a ser lembrada. 2014. Disponível em: [http://www.ternuma.com.br/index.php/art/1872-31-de-marco-de-1964-gen-bragasensaciona]. [Acesso em: 01 de abril de 2014].

BRANDÃO, Helena H. N. 2004. Introdução à Análise do Discurso. Campinas, SP: UNICAMP. 
CARDOSO, Lucileide. 2012. Criação da Memória: Defensores e Críticas da Ditadura (1964-1985). Cruz das Almas, Ed. UFRB.

2011. Os discursos de celebração da "Revolução de 1964. Disponível em [http:// www.scielo.br/scielo]. [Acesso em: 15 de março de 2014].

CHAMMAS. Eduardo Z. 2011. O Correio da Manhã no golpe de 1964: impasses e dilemas na relação com os militares. Anais do XXVI Simpósio Nacional de História. ANPUH: São Paulo.

CHAGAS, P. O regime militar alcançou todos os objetivos do movimento de 1964?. 2014. Disponível em: [http://www.ternuma.com.br/index.php/art/1893-o-regime-militar-alcancou-todosos-objetivos-do-movimento-de-1964-pchagas] Acesso em: 10 de abril de 2014.

CARVALHO, Marcelo Sávio R. 2006. A Trajetória da Internet no Brasil: do surgimento das redes de computadores à instituição dos mecanismos de governança. Rio de Janeiro: Dissertação. Universidade Federal do Rio de Janeiro.

DREIFUSS, René A. 1986. 1964: A conquista do Estado. Ação Política, Poder e Golpe de Classe. $4^{a}$ Edição. Tradução: Faculdade de Letras da UFMG. Petropólis, Vozes.

FERREIRA, Jorge. 2004. A estratégia do confronto: a Frente de Mobilização Popular. Rev. Bras. Hist. São Paulo. vol.24 no. 47.

FIORIN, José Luiz. 1988. O regime de 1964: discurso e ideologia. São Paulo: Atual.

GARCIA, A. 31 de Março, Abordagem clara, análise coerente e imparcial. 2014. Disponível em: http://ternuma.com.br/index.php/art/1875-31-de-marco-abordagem-clara-analisecoerente-e-imparcial] [Acesso em: 10 de fevereiro de 2015].

LE GOFF, Jacques. 1996. História e memória. Campinas: Unicamp.

LEMOS André. PALACIOS, Marcos (Org). 2002. Janelas do Ciberespaço. Porto Alegre: Sulina. LEMOS, Renato. 2002. Anistia e Crise Política no Brasil pós 64. Tópoi: Rio de Janeiro.

LEVY, Pierre. Cibercultura. Rio de janeiro: Editora 34.

NAPOLITANO, Marcos. 2014. 1964: História do Regime Militar brasileiro. São Paulo: Contexto.

POLLAK, Michael. 1989. Memória, Esquecimento, Silêncio. Estudos históricos. Rio de Janeiro.

SALES, Jean R. 2011. O Partido Comunista do Brasil nos anos sessenta: estruturação orgânica e atuação politica. Cadernos da AEL: tempo de ditadura. Campinas, UNICAMP/IFCH/AEL, V. 8, N14/15.

SEABRA, Raphael. 2010. A revolução venezuelana: chavismo e bolivarianismo. Sociedade e cultura. Brasilia, V13, n 02.

SILVA, Juremir M. 2014. 1964. Golpe midiático-civil-militar. Porto Alegre: Sulina.

TOLEDO, Caio N. 2006. A luta ideológica na conjuntura do golpe de 1964. Idéias, v. 12/13.

\footnotetext{
$\mathrm{n}^{\circ} 19$.

, Caio N. 2004. 1964: golpismo e democracia. As falácias do revisionismo. Crítica Marxista,
} 
TV TERNUMA. Baú da Verdade. Disponível em: hhtpp://terneuma.com.br/índex.php/obau-da-verdade]. [Acesso em: 08 de janeiro de 2015].

TV TERNUMA. Contraponto. Disponível em: [http://ternuma.com.br/index.php/2013-0822-03-35-31]. [Acesso em: 08 de janeiro de 2015].

TV TERNUMA. Estatuto. 2011. Disponível em: [http://ternuma.com.br/index.php/nossoestatuto]. [Acesso em: 15 de outubro de 2014].

TV TERNUMA. Justicamentos. Disponível em: http://ternuma.com.br/index.php/justicamentos]. [Acesso em: 08 de janeiro de 2015].

TV TERNUMA. Memorial 31 de Março. Disponível em: [http://ternuma.com.br/index.php/memorial-31-de-marco]. [Acesso em: 15 de outubro de 2014].

TV TERNUMA. Onde eles estão. Disponível em: [http://ternuma.com.br/index.php/ondeeles-estao]. [Acesso em: 10 de outubro de 2014].

TV TERNUMA. Para Meditar. Disponível em: [http://ternuma.com.br/index.php/parameditar]. [Acesso em: 10 de outubro de 2014].

TV TERNUMA. Quem somos. Disponível em: http://ternuma.com.br/index.php/quemsomos]. [Acesso em: 15 de outubro 2014].

TV TERNUMA. Revanchismo. Disponível em: http://ternuma.com.br/index.php/revanchismo]. [Acesso em: 08 de janeiro de 2015].

TV TERNUMA. Verdades Históricas. Disponível em: [http://ternuma.com.br/index.php/2013-08-22-03-34-31]. [Acesso em 10 de outubro de 2014]. 